J. Product. \& Dev., 23(3): 483- 503(2018)

\title{
A TRIAL OF APPLYING THE HYPER-SPECTRAL SENSING TECHNIQUE IN THE IDENTIFICATION OF SOME SOIL ATTRIBUTES
}

\author{
Adel A. Elwan ${ }^{1 *}$ M.E.A. Khalifa ${ }^{1}$, and M.K. Abdel-Fattah ${ }^{2}$ \\ ${ }^{1}$ Pedology Department, Water Resources and Desert Lands Division, \\ Desert Research Center, Cairo, Egypt. \\ ${ }^{2}$ Soil and Water Department, Faculty of Agriculture, Zagazig University, \\ Zagazig, Egypt. ${ }^{*}$ Corresponding author: Tel.:+201011824240, E-mail address: \\ dr.elwan_drc@yahoo.com
}

\begin{abstract}
Historically, our understanding of the soil and assessment of its quality and function has been gained through field survey and routine soil physicochemical laboratory analysis. Reflectance spectroscopy can be used to non-destructively characterize materials for a wide range of applications. Hyperspectral remote sensing data provide a rich source of information produced in the form of the spectrum which can be used to identify surface materials. In this study, Field Portable Hyperspectral Radiometer (FPHR) was evaluated in an attempt for prediction of diverse soil properties related to three different soil orders (Vertisols, Aridisols, and Entisols) across Lower Egypt. Eight pedons consisting of 34 samples were collected from different semi-arid areas.

Soil horizonation and twelve soil attributes including clay, sand, silt, $\mathrm{SOC}, \mathrm{pH}, \mathrm{EC}, \mathrm{A}$.W, gypsum, $\mathrm{CaCO}_{3}, \mathrm{Fe}_{2} \mathrm{O}_{3}, \mathrm{Al}_{2} \mathrm{O}_{3}$, and $\mathrm{SiO}_{2}$ were traditionally analyzed and then correlated with spectral reflectance of the spectrum range. Four bands (blue, green, red, and near-infrared) were calculated for prediction of these variables. The results showed that the variations in spectral reflectance for each horizon across the spectrum range (276-1093 $\mathrm{nm})$ were matched well with those of morphologically described horizons in the field. Additionally, the correlation results of different soil variables were highly correlated with spectral reflectance at different band wavelengths. For example, clay content correlated negatively $(r=-0.93)$ with reflectance at the green band while silt ( $r=0.67$ at the blue band) and sand (0.87 at the green band) correlated positively. Regression equations were fitted in graphs to attempt the quantification of the soil constituents from their reflectance values. The best predictive models were obtained for clay
\end{abstract}


content $\left(R^{2}=0.93\right), \mathrm{SiO}^{2}\left(R^{2}=0.86\right), \mathrm{Al}_{2} \mathrm{O}_{3}\left(R^{2}=0.85\right), A . W .\left(R^{2}=\right.$ $0.79), \mathrm{CaCO}_{3}\left(R^{2}=0.79\right)$, gypsum $\left(R^{2}=0.75\right), \mathrm{Fe}_{2} \mathrm{O}_{3}\left(R^{2}=0.71\right)$, sand $\left(R^{2}=0.69\right)$, silt $\left(R^{2}=0.54\right)$, and SOC $\left(R^{2}=0.51\right)$ while the poor prediction was for $E C$ and $p H$. The results concluded that the spectral reflectance of the spectrum had the potential to differentiate the soil horizonation and to predict the selected soil variable at different wavelength bands.

Conclusively, FPHR was shown to be an effective tool for enhanced soil horizon differentiation and the acquisition of soil attributes information.

Keywords: Hyperspectral, Horizonation, Soil attributes prediction, Soil reflectance.

\section{INTRODUCTION}

The soil is a heterogeneous system whose processes and mechanisms are complex and difficult to fully comprehend (Viscarra Rossel et al., 2006). Many conventional soil analytical techniques are used in an attempt to establish the relationship between soil physical and chemical properties and individual soil components, often disregarding their complex, multicomponent interactions. Indeed, soil chemical extractions that alter the equilibrium between the phases may further complicate the interpretation of results. Historically our understanding of the soil system and assessment of its quality and function has been gained through this type of laboratory analysis. We need to further develop our analytical techniques to better understand the soil as a complete system and a resource so that we may make more efficient use of it and simultaneously preserve it for future generations. This is more important now than ever before since the acquisition of larger amounts of accurate soil data is essential if we are to manage our base resources sensibly to meet the food demands of future populations (Bilgili et al., 2010). Remotely sensed hyperspectral data have great potential for quantitative assessment of soil and vegetation parameter at spatial scale. The development of methods to map soil properties using optical remote sensing data in combination with field measurements has been the objective of several studies during the last decade. Also, it has been a challenge to find the most appropriate technique for studying soil properties from optical data and thus reducing the time and effort involved in field sampling and laboratory analysis. Hyperspectral sensors operate with more than hundreds of bands with good spatial and spectral resolution producing continuous spectra. With the progress and maturity of the technology, hyperspectral remote sensing has found a wide range of 
applications in mapping soil types and quantifying soil constituents (Minu et al., 2016).

Infrared spectroscopic techniques are highly sensitive to both organic and inorganic phases of the soil, making their use in the agricultural and environmental sciences particularly relevant. Intense fundamental molecular frequencies related to soil components occur in the mid-infrared (MIR) between wavelengths 2500 and $25,000 \mathrm{~nm}$. The visible and infrared portions of the electromagnetic spectrum are highlighted in Fig. 1. Weak overtones and combinations of these fundamental vibrations dominate the near-infrared (NIR) (700-2500 nm) and electronic transitions the visible (VIS) (400-700 $\mathrm{nm})$ portions of the electromagnetic (EM) spectrum. Quantitative spectral analysis of soil using visible and infrared reflectance spectroscopy requires sophisticated statistical techniques to discern the response of soil attributes from spectral characteristics. Various methods have been used to relate soil spectra to soil attributes. For example, Elwan and Sivasamy (2013) used multiple regression and correlation analyses to relate specific bands in the NIR to a number of soil properties in a semi-arid area of India. Shibusawa et al. (2001) used stepwise multiple linear regression for the estimation of various soil properties from the NIR spectra of soil. Shepherd and Walsh (2002) used multivariate adaptive regression splines for the estimation of soil properties from soil spectral libraries.

Soil reflectance characteristics are determined over the entire visible $(350-700 \mathrm{~nm})$ and near-infrared $(700-2500 \mathrm{~nm})$ region with the use of a monochromator (Viscarra Rossel et al., 2006). Raw data, first-, and secondderivatives each provide valuable information that can be analyzed separately or combined using multivariate statistical methods or data mining techniques. Soil constituents have unique absorption features in these wavelength regions due to overtones related to stretching and bending vibrations in molecular bonds (Viscarra Rossel et al., 2006). Chang et al. (2001) predicted more than thirty soil properties simultaneously with variable levels of success using a principal component analysis method with cross-validation. They reported successful predictions $\left(\mathrm{R}^{2}>0.80\right)$ for total organic carbon and nitrogen $\left(\mathrm{g} \mathrm{kg}^{-1}\right)$, gravimetric soil water content, soil water content, exchangeable calcium, cation exchange capacity (CEC) and silt and sand content. Brown et al. (2006) used over 4100 surface and subsurface soils from across the United States, Africa and Asia to evaluate the accuracy of VNIR empirical models for global soil characterization and reported strong predictability for kaolinite, montmorillonite, clay content, as well as CEC, soil organic carbon, inorganic carbon, and extractable Fe. Others also used VNIR spectroscopy to 


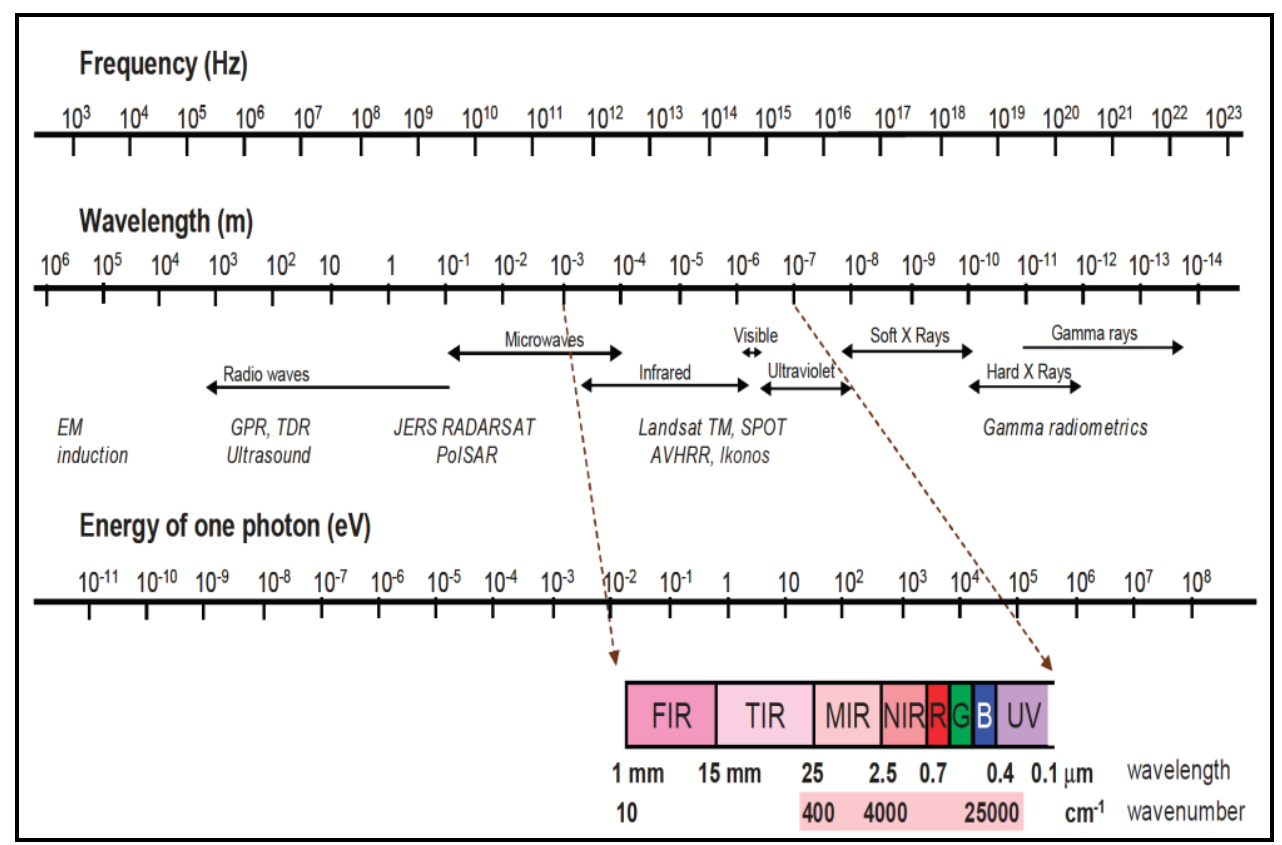

Fig. 1. The electromagnetic (EM) spectrum highlighting the visible and infrared portions (after Viscarra Rossel et al., 2006).

successfully predict organic carbon and nitrogen (Reeves et al., 2002), $\mathrm{Fe}_{2} \mathrm{O}_{3}$, $\mathrm{Al}_{2} \mathrm{O}_{3}, \mathrm{CaCO}_{3}$, potentially mineralizable nitrogen (Reeves and Van Kessel, 1999), heavy metals, micronutrients (Udelhoven et al., 2003), C:N ratio and soil biological properties (Ludwig et al., 2002). Additionally, the prediction of soil constituents that do not absorb within the VNIR range may be possible through their correlations with spectrally active constituents.

Therefore, the objectives of this study were to: (i) determine the efficiency of FPHR with comparison to traditional field and laboratory methods in enhancing soil horizon differentiation, (ii) determine whether FPHR spectroscopy can be used easily as a rapid, inexpensive alternative or supplement to traditional methods for measuring soil properties by correlation coefficients, and (iii) find the appropriate bands across the spectrum range that can properly predict the soil variable using the regression analysis.

\section{MATERIALS AND METHODS}

\section{Pedon Sampling}

The study was conducted on three soil orders (Vertisols, Aridisols, and Entisols), which cover the major variations in soil types in Egypt. Standard eight 
pedons consisting of 34 samples (Fig. 2) were collected from different semi-arid sites in Lower Egypt. Two pedons were collected from Nile old deltaic plain (P1 and P2) and one pedon (P3) from bajada plain at wadi Al-Molak of East Delta; one pedon (P4) from Inshas, Sharkia Governorate; two pedons (P5 and P6) from Abu-Soltan, Ismailia Governorate; one pedon (P7) from Al-Tur, South Sinai; and one pedon (P8) from Al-Hamam area, Northeastern coast of Egypt. P1 was classified as Vertisols, P2 and P3 were classified as Aridisols, and P4 to P8 were classified as Entisols. Study areas have a semi-arid climate with a mean annual precipitation, evaporation, temperature and relative humidity of $13 \mathrm{~mm}, 881 \mathrm{~mm}$, $22{ }^{\circ} \mathrm{C}$ and $55 \%$, respectively.

In the field, a range of soil features is generally used during the process of horizon description, including soil color, texture, and structure, which are essentially affected by the physical and chemical composition of the soil. For example, besides soil organic matter (SOM) and soil water content, Fe and Mn are the primary coloring agents for many soils. Morphological descriptions for all pedons were morphologically described and the horizons were differentiated based on visual examination and hand texturing according to Schoeneberger et al., (2012). Collected samples were transported to the laboratory in sealed plastic bags.

\section{Laboratory Analyses}

In the laboratory, soil samples were air-dried and gently ground to pass through a $2 \mathrm{~mm}$ sieve, then subjected to standard soil characterization. The prepared samples were then scanned on the sample surface using FPHR (described below). Particle size analysis was accomplished via pipette method and sieved sands using a $63 \mu \mathrm{m}$ sieve (Gee and Bauder, 1986). Soil organic carbon (SOC) was quantified via titration following the Walkley-Black dichromate oxidation method (Nelson and Sommers, 1996). Gypsum concentration was determined by the differential water loss method (Artieda et al., 2006). Carbonates were determined using a calcimeter (Kacar, 1994); soil pH with a 1:2 soil/water suspension using a glass electrode $\mathrm{pH}$ meter (McLean, 1982); electrical conductivity (EC) in soil extraction using a conductivity meter (Janzen, 1993). Furthermore, the soil samples were analyzed for soil available water (A.W.), $\mathrm{SiO}_{2}$, $\mathrm{Al}_{2} \mathrm{O}_{3}$, and $\mathrm{Fe}_{2} \mathrm{O}_{3}$ following standard procedures (Jackson, 1973; Soil Survey Staff, 2014).

\section{Field Portable Hyperspectral Radiometer (FPHR)}

The GER 1500 model is a field portable hyperspectral radiometer (FPHR) covering the UV, Visible, and NIR wavelengths from $276 \mathrm{~nm}$ to $1093 \mathrm{~nm}$ (Fig. 3). It was used to scan each soil sample. The instrument uses a diffraction grating with a silicon diode array. The silicon array has 512 discrete detectors that provide 


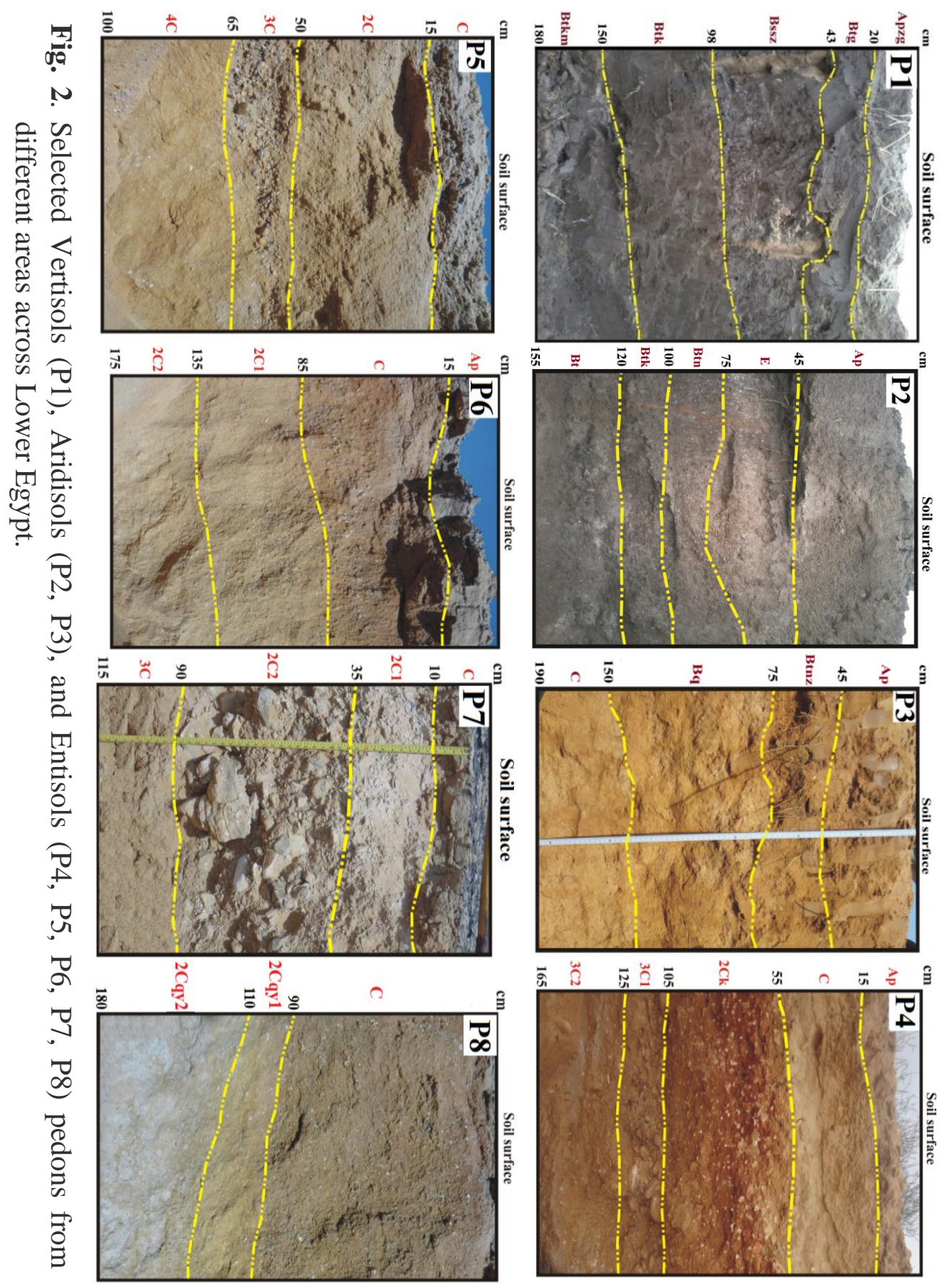




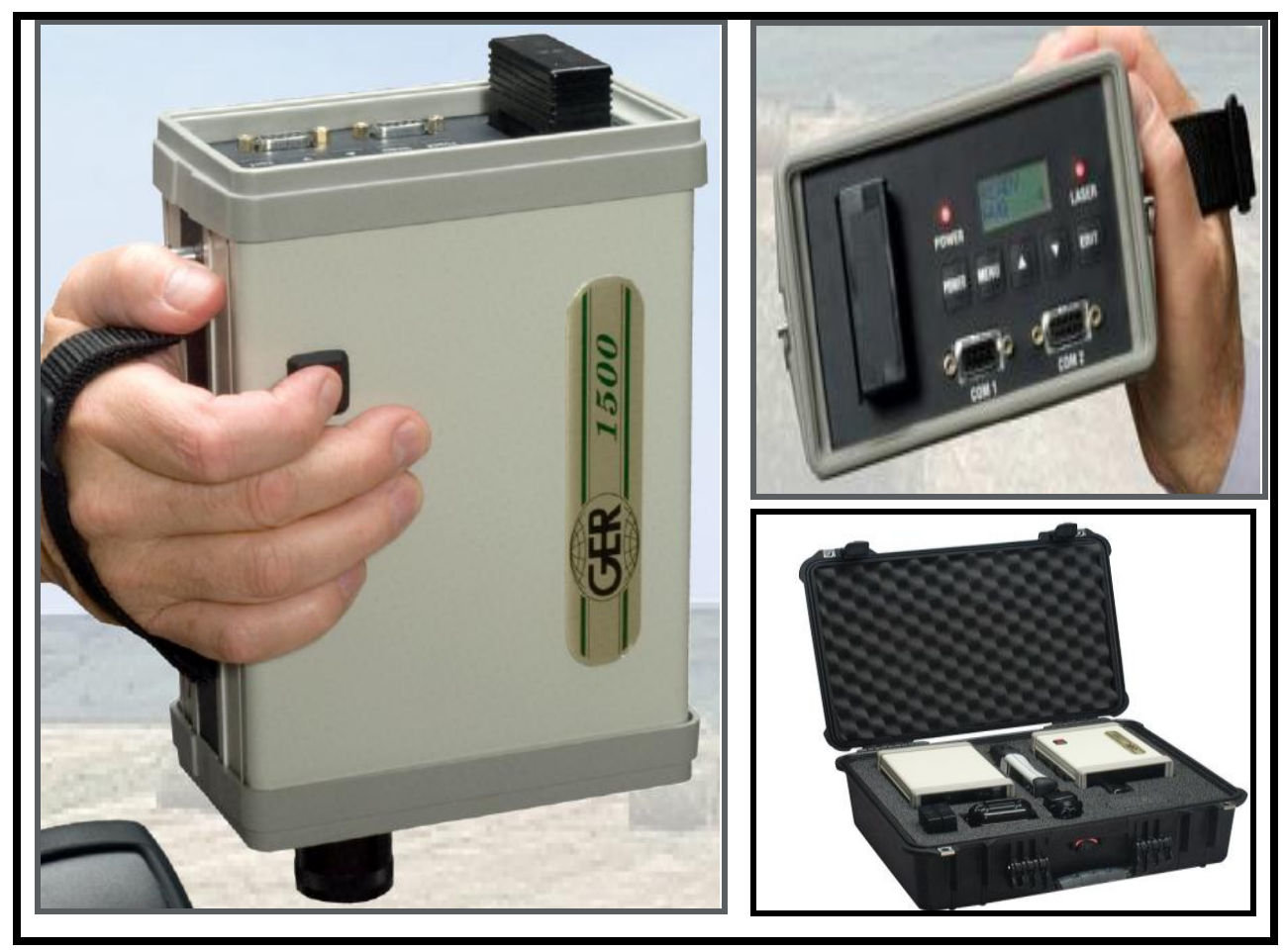

Fig. 3. Field portable hyperspectral radiometer (FPHR) sensor used in the current study.

the capability to read 512 spectral bands. The spectroradiometer includes memory for stand-alone operation as well as the capability for computerassisted operation through its COM2, RS232 serial port. The spectral readings can be stored for subsequent downloading and analysis using a personal computer with a standard RS232 serial port and GER licensed operating software. Computers incorporating only USB serial ports may be connected to the GER 1500 by using the SVC ADP000015 USB Serial port adapter. An optional external GPS device may be connected via the instrument's COM1 RS232 serial port. When connected, GER 1500 records the latitude, longitude, and time of each spectral reading. For all scanning, recalibration and verification with NIST standards were conducted every 20 scans and the aperture of the instrument was covered with a thin plastic wrap to prevent soil or dust from contaminating the aperture window. Data from the instrument was exported to MS Excel for analysis and display. 


\section{Hyperspectral reflectance and data processing}

Thirty-four soil samples of selected eight pedons were air-dried, crushed, and sieved $(2 \mathrm{~mm})$; then the samples were scanned using FPHR in the laboratory condition. Soil samples were individually spread on a white paper (30 $\times 42 \mathrm{~cm}$ diameter) forming a layer of $1.8 \mathrm{~cm}(1.5 \mathrm{~cm}$ is considered as optically infinitely thick for soil). The sample surface was scraped plane with a ruler, as pressing can affect the porosity of the soil and result in a false measurement. The absolute reflectance of samples was recorded for 276-1093 $\mathrm{nm}$ at $1.5 \mathrm{~nm}$ spectral resolution, yielding a total of 512 data channels per spectrum. Reflectance spectra were measured mid noon in between $11.30 \mathrm{am}$ to $12.30 \mathrm{pm}$, for allowing good sunlight. The zenith angle of the FPHR was set to $45^{\circ}$ by pointing the instrument at a distance of $30 \mathrm{~cm}$ above the soil surface. A standard panel coated with barium sulphate $\left(\mathrm{BaSO}_{4}\right)$ was used as a reference for the reflectance calibration before each set of measurements. Each reflectance measurement produced a single spectrum. Reference measurements were taken before the first measurements set and after every five minutes onwards to adapt the changing atmospheric conditions. The percent reflectance spectrum was calculated as the ratio between the reflected spectra from the target (soil sample) and the incident spectra from the panel (reference) using the following formula.

Percent spectral reflectance $=\frac{\text { Reflectance from the soil sample }}{\text { Reflectance from the reference panel }} \times 100$

The spectral reflectance data, both absolute and percent reflectance values, were transferred from the FPHR to a personal computer as ASCI files with .asc extension utilizing a specific software supplied with the instrument. These files were later opened in a spreadsheet programme and further analyses were carried out. In the current study, raw spectra were tested both separately and jointly in predicting soil horizonation. Furthermore, the reflectances in blue, green, red, and near-infrared (NIR) bands were selected due to their most sensitive wavelengths to soil components and calculated for each sample by taking mean of reflectance values in the wavelengths ranges of $450-520 \mathrm{~nm}$, $520-600 \mathrm{~nm}, 630-690 \mathrm{~nm}$ and $760-900 \mathrm{~nm}$, respectively, to match the bands in the Landsat Thematic Mapper (TM) sensors (Fig. 1).

\section{Statistical analysis}

Reflectance data were translated from binary to ASCII and exported in batches using ViewspecPro (Analytical Spectral Devices, Inc., Boulder, CO, 80301). The ASCII files were later opened in a spreadsheet programme and further analyses were carried out. The sequential percent spectral reflectance 
readings obtained from each sample (512 values) at approximately $1.5 \mathrm{~nm}$ bandwidth interval across the spectrum wavelengths were performed using Microsoft Excel spreadsheet software, producing a master data file with one representative reflectance spectrum per soil sample. Calibrations between soil reflectance and soil parameters were performed using both correlation (r) and multiple regression models for selecting bandwidth that is the best for prediction of soil properties.

Correlation between each band and each soil property were worked out separately for spectral datasets and evaluated the relationship of correlation of reflectance with soil properties with the change in bandwidth. Multiple regression models for each soil property were developed using each spectral data sets. Model predictability (Model $\mathrm{R}^{2}$ ) was evaluated for selecting the best bandwidth for prediction of soil properties. Optimum bandwidth found was to be used in the study for prediction of soil properties. Regression equations were fitted and plotted as graphs to quantify the soil constituents using reflectance in the band in which the highest correlation was registered, as suggested by Chang et al., (2001). Bivariate correlations analysis was done between soil properties and spectral data sets using SPSS software. Correlation analysis was performed for each soil property with each band. Best correlated bands from each reflectance related datasets were selected separately for each soil property, considering the absolute values of correlation coefficients.

The prediction model was developed for each soil properties considering all the bands as a variable. Model predictability $\left(\mathrm{R}^{2}\right)$ was used for evaluating the spectral data sets for prediction of soil properties. The spectral dataset with the highest $\mathrm{R}^{2}$ was selected for model development for each soil property. The correlation with each soil properties and reflectance data at different bandwidth was computed and plotted against wavelength. Correlation between soil properties and reflectance at different wavelength for spectral data sets was evaluated for all soil properties. Multiple linear regression is a common multivariate tool which, at its simplest level, forms a model that specifies the relationship between a response variable (Y) and a set of dependent variables (X). The soil property was considered the dependent variable, and the band reflectance was the independent variables. After a choice of the number of bands, multiple linear regression was carried out for each soil attribute and best-correlated bands from each spectral dataset were selected. Best dataset and optimum number of bands to be included in the model have been selected based on the highest $\mathrm{R}^{2}$ value. 


\section{RESULTS AND DISCUSSION}

\section{Field morphological horizonation}

The selected morphological characters of studied pedons are furnished in Table 1 and visualized in Fig. 2. Moreover, the textural classes across all landscapes are widely varied from sand to clay, indicating the heterogeneity of soil forming processes and variety of parent materials. Sand fraction concentration ranged from $9.3 \%$ in $\mathrm{P} 1$ to 95.4 in $\mathrm{P} 8$ while clay content varied from $1.2 \%$ in the subsurface layer of P8 to $62 \%$ in the deepest horizon of P1 (Table 1). Most pedons selected for this study were derived from alluvium as it is the dominant parent material of Lower Egypt. Pedons P1 and P2 were developed on Nile old deltaic plain at toeslope landscape position in wadi Al-Molak, East Delta while P3 was developed on bajada plain at toeslope of wadi Al-Molak. Pedon P4 was derived from ferruginous sandstone on the alluvial plain of Inshas area while pedons (P5 and P6) from alluvial plain at Abu-Soltan region. Furthermore, pedon P7 was formed on alluvial fans and outwash plain at Al-Tur area while pedon P8 were formed locally from weathered marine limestone on inland portion of the northeastern coastal region.

A soil horizon is defined as a layer of soil or soil material approximately parallel to the land surface and differing from adjacent genetically related layers in physical, chemical, and biological properties or characteristics such as color, structure, texture, consistency, kinds and number of organisms present, or degree of acidity or alkalinity (Soil Science Society of America, 2017). As the formation of horizons is a function of a variety of physical, chemical, geological, and biological processes associated with the landscape and climate over long time periods, the differentiation of soil horizons is essential for the understanding and classification of soil (Schaetzl and Anderson, 2005). The process of field horizonation to some degree is a process of subjective approximation of soil features by field soil surveyors. Surveyors use all the tools available to differentiate soil horizons and establish minimal within-horizon variability, considering a variety of soil properties. As such, significant variations of soil properties should occur between soil horizons in a given pedon. Clearly, the most important part of horizonation is the identification of differences between soil horizons. Pedon P1 has highly developed horizonation sequence: Apzg-Btg-BsszBtk-Btkm and classified as Aquic Salitorrerts, which characterized by anthraquic condition (APzg and Btg), salic horizon (Bssz). Likewise, the horizon sequences of Aridisols pedons are Ap-E-Btn-Btk-Bt for P2 (Petronodic Natrargids) and ApBtnz-Bq-C for P3 (Calcic Haplosalids). On the other hand, the layer sequences in the Entisols pedons are: Ap-C-2CK-3C1-3C2 for P4; C-2C-3C-4C for P5; Ap-C2C1-2C2 for P6; C-2C1-2C2-3C for P7; and C-2Cqy1-2Cqy2 for P8 (Fig. 2). 
Table 1. Soil characterization data for thirty-four soil samples of eight pedons from different areas across Lower Egypt

\begin{tabular}{|c|c|c|c|c|c|c|c|c|c|c|c|c|c|c|}
\hline \multirow{2}{*}{ 冚 } & \multirow{2}{*}{$\begin{array}{c}\text { Horizon / } \\
\text { layer }\end{array}$} & \multirow{2}{*}{$\begin{array}{l}\text { Lower } \\
\text { depth } \\
\text { (cm) }\end{array}$} & \multicolumn{3}{|c|}{ Fine earth $(\%)$} & \multirow{2}{*}{$\underset{\%}{\mathrm{SOC}}$} & \multirow{2}{*}{$\mathrm{pH}$} & \multirow{2}{*}{$\begin{array}{c}\mathrm{EC} \\
\mathrm{dS} / \mathrm{m}\end{array}$} & \multirow{2}{*}{$\underset{\%}{\text { A.W }}$} & \multirow{2}{*}{$\underset{\%}{\text { Gypsum }}$} & \multirow{2}{*}{$\underset{\%}{\mathrm{CaCO}_{3}}$} & \multirow{2}{*}{$\begin{array}{c}\mathrm{Fe}_{2} \mathrm{O}_{3} \\
\%\end{array}$} & \multirow{2}{*}{$\underset{\%}{\mathrm{Al}_{2} \mathrm{O}_{3}}$} & \multirow{2}{*}{$\mathrm{SiO}_{2} \%$} \\
\hline & & & Sand & Silt & Clay & & & & & & & & & \\
\hline \multirow{5}{*}{ P1 } & Apzg & 20 & 13.0 & 35.5 & 51.5 & 0.81 & 8.8 & 22.3 & 50.5 & 1.2 & 3.8 & 6.2 & 21.3 & 42.3 \\
\hline & Btg & 43 & 15.5 & 30.0 & 54.5 & 0.60 & 8.6 & 19.5 & 58.4 & 2.2 & 5.2 & 6.8 & 20.4 & 41.5 \\
\hline & Bssz & 98 & 9.3 & 39.5 & 51.2 & 0.59 & 8.6 & 30.7 & 52.5 & 1.5 & 6.5 & 4.7 & 18.5 & 42.6 \\
\hline & Btk & 150 & 11.2 & 29.3 & 59.5 & 0.53 & 8.8 & 15.0 & 51.6 & 1.1 & 8.1 & 6.2 & 31.3 & 39.4 \\
\hline & Btkm & 180 & 13.5 & 24.5 & 62.0 & 0.48 & 8.7 & 8.8 & 46.2 & 0.9 & 7.5 & 7.8 & 34.1 & 38.4 \\
\hline \multirow{5}{*}{ P2 } & Ap & 45 & 17.0 & 31.2 & 51.8 & 0.80 & 8.6 & 12.5 & 40.5 & 0.7 & 5.8 & 3.7 & 29.4 & 41.3 \\
\hline & $\mathrm{E}$ & 75 & 23.1 & 37.5 & 39.4 & 0.68 & 8.5 & 5.8 & 36.2 & 0.6 & 6.2 & 2.1 & 21.5 & 43.5 \\
\hline & Btn & 100 & 19.5 & 23.3 & 57.2 & 0.46 & 8.8 & 7.5 & 43.3 & 0.3 & 8.4 & 7.2 & 33.4 & 39.8 \\
\hline & Btk & 120 & 25.2 & 19.5 & 55.3 & 0.45 & 8.7 & 6.3 & 42.8 & 0.8 & 9.1 & 6.8 & 28.6 & 41.2 \\
\hline & $\mathrm{Bt}$ & 155 & 13.4 & 34.1 & 52.5 & 0.41 & 8.5 & 5.2 & 40.0 & 0.3 & 8.8 & 8.2 & 27.7 & 43.8 \\
\hline \multirow{4}{*}{ P3 } & Ap & 45 & 9.8 & 52.4 & 37.8 & 0.27 & 8.4 & 11.8 & 25.3 & 0.5 & 7.2 & 5.7 & 18.3 & 46.5 \\
\hline & Btnz & 75 & 37.0 & 37.8 & 25.2 & 0.38 & 8.5 & 30.1 & 21.5 & 0.2 & 8.8 & 6.6 & 17.5 & 45.2 \\
\hline & $\mathrm{Bq}$ & 150 & 45.7 & 38.5 & 15.8 & 0.11 & 8.3 & 6.7 & 15.8 & 0.3 & 9.3 & 4.2 & 14.4 & 47.3 \\
\hline & $\mathrm{C}$ & 190 & 49.4 & 36.2 & 14.4 & 0.08 & 8.1 & 5.9 & 11.5 & 0.1 & 10.2 & 5.1 & 13.1 & 48.3 \\
\hline \multirow{5}{*}{ P4 } & Ap & 15 & 63.35 & 25.4 & 11.3 & 0.12 & 7.8 & 2.1 & 7.6 & 0.2 & 6.5 & 9.5 & 4.3 & 56.2 \\
\hline & $\mathrm{C}$ & 55 & 64.7 & 26.7 & 8.6 & 0.08 & 7.9 & 2.5 & 6.4 & 0.3 & 8.5 & 11.6 & 4.6 & 58.6 \\
\hline & $2 \mathrm{Ck}$ & 105 & 60.5 & 29.1 & 10.4 & 0.04 & 8.2 & 2.7 & 7.2 & 0.4 & 10.5 & 19.2 & 4.8 & 57.8 \\
\hline & $3 \mathrm{C} 1$ & 125 & 61.5 & 31.8 & 6.7 & 0.03 & 8.1 & 1.8 & 5.3 & 0.1 & 9.5 & 12.4 & 6.3 & 60.1 \\
\hline & $3 \mathrm{C} 2$ & 165 & 71.0 & 21.9 & 7.1 & 0.07 & 7.9 & 1.7 & 6.1 & 0.2 & 8.4 & 8.5 & 5.7 & 53.1 \\
\hline \multirow{4}{*}{ P5 } & $\mathrm{C}$ & 15 & 58.0 & 31.4 & 10.6 & 0.12 & 7.3 & 1.4 & 6.8 & 0.4 & 5.6 & 2.6 & 3.4 & 67.1 \\
\hline & $2 \mathrm{C}$ & 50 & 56.7 & 34.9 & 8.4 & 0.08 & 7.4 & 1.3 & 5.4 & 0.9 & 4.7 & 2.5 & 3.6 & 64.3 \\
\hline & $3 \mathrm{C}$ & 65 & 64.0 & 28.1 & 7.9 & 0.09 & 7.3 & 1.5 & 5.6 & 0.6 & 3.8 & 2.7 & 3.7 & 68.4 \\
\hline & $4 \mathrm{C}$ & 100 & 64.0 & 27.6 & 8.4 & 0.07 & 7.6 & 0.9 & 4.8 & 0.8 & 5.7 & 3.9 & 3.8 & 69.4 \\
\hline \multirow{4}{*}{ P6 } & Ap & 15 & 75.4 & 15.4 & 9.2 & 0.19 & 7.9 & 1.2 & 6.9 & 0.4 & 4.6 & 3.1 & 4.6 & 84.5 \\
\hline & $\mathrm{C}$ & 85 & 76.3 & 17.3 & 6.4 & 0.11 & 7.6 & 0.7 & 6.4 & 0.9 & 5.7 & 2.6 & 3.8 & 85.6 \\
\hline & $2 \mathrm{C} 1$ & 135 & 78.9 & 16.4 & 4.7 & 0.04 & 7.8 & 1.3 & 6.7 & 0.8 & 1.5 & 3.0 & 4.1 & 87.3 \\
\hline & $2 \mathrm{C} 2$ & 175 & 82.3 & 11.3 & 6.4 & 0.02 & 7.1 & 0.6 & 5.1 & 0.4 & 2.7 & 2.5 & 4.6 & 88.1 \\
\hline \multirow{4}{*}{ P7 } & $\mathrm{C}$ & 10 & 82.0 & 10.9 & 7.1 & 0.02 & 7.2 & 1.2 & 4.2 & 1.25 & 27.2 & 2.6 & 3.9 & 74.3 \\
\hline & $2 \mathrm{C} 1$ & 35 & 81.7 & 14.8 & 3.5 & 0.03 & 7.3 & 2.0 & 3.7 & 1.6 & 31.5 & 1.2 & 4.8 & 76.2 \\
\hline & $2 \mathrm{C} 2$ & 90 & 85.1 & 12.3 & 2.6 & 0.01 & 7.6 & 2.5 & 4.5 & 1.7 & 29.7 & 1.3 & 4.2 & 74.5 \\
\hline & $3 \mathrm{C}$ & 115 & 90.5 & 8.2 & 1.3 & 0.05 & 7.4 & 1.7 & 3.2 & 1.9 & 20.8 & 1.4 & 4.1 & 71.3 \\
\hline \multirow{3}{*}{ P8 } & $\mathrm{C}$ & 90 & 90.4 & 4.3 & 5.3 & 0.01 & 8.1 & 1.4 & 3.6 & 7.9 & 9.5 & 0.5 & 3.6 & 78.3 \\
\hline & 2Cqy 1 & 110 & 92.4 & 6.4 & 1.2 & 0.02 & 8.3 & 3.6 & 2.4 & 14.3 & 11.3 & 0.7 & 3.7 & 74.6 \\
\hline & 2Сqy 2 & 180 & 95.4 & 1.9 & 2.7 & 0.01 & 8.4 & 5.8 & 2.5 & 17.5 & 10.4 & 0.9 & 5.4 & 79.5 \\
\hline
\end{tabular}


The boundary between two layers was clearly identified in the field based on color, texture, structure, hardness, or other features which largely influenced by the pedogenic process. Boundaries between the horizons in studied pedons are varied in both distinctiveness and topography. Abrupt smooth boundaries were the dominant within the most investigated pedons. The occurrence of smooth and abrupt to diffuse boundaries in studied pedons is often cited as field evidence for a lithologic discontinuity (LD) (Schaetzl and Anderson, 2005). In P4, the soil exhibited abrupt smooth C-2Ck and 2Ck-3C1 boundaries in P4 indicating two unlike parent material with different modes of deposition occurring on more stable surfaces, however, the wavy boundary was found between Ap-C horizons indicating same materials (Fig. 2).

\section{Prediction of soil horizonation}

Basic soil constituents affecting soil reflectance characteristics are anthraquic features of Vertisols, soil water, clay content, organic matter, and $\mathrm{Fe}-\mathrm{Al}$ oxides (Bowers and Hanks, 1965). Fig. 4 shows raw reflectance spectra and their prediction in pedon horizonation (Fig. 2). Soil reflectance was generally lower in the visible range of blue and green bands (450-600 $\mathrm{nm})$ and higher in the red and near-infrared range $(630-900 \mathrm{~nm})$. With regard to FPHR analysis of pedon horizonation, the studied pedons qualitatively showed good alignment with field-established horizonation. Absorption peaks for Vertisols were higher and the percent soil reflectance was low (16-20\%) while for Aridisols it was slightly low (20-25\%) in P2 and slightly high (32-40\%) in P3. By contrast, the soil reflectances of Entisols pedons were higher compared to Vertisols and Aridisols and varied from $35 \%$ in C layer of P4 to $75 \%$ in P8 (2Cqy2). Horizonation was easily identified based on the reflectance characters for each soil sample (horizon or layer) (Fig. 4).

Given the raw reflectance data from FPHR (Fig. 4) vs. morphological horizonation (Table 1) from field survey, it is suggested that FPHR could be used as a tool to assist in field morphological horizon differentiation. For example, FPHR could be used to identify multiple argillic horizons within a Vertisol pedon and lithologic discontinuity in P4 at depths of 55 and 105 $\mathrm{cm}$. In summary, the results concluded that the data afforded by the use of FPHR sensor offer pedologists unique insights into predicted differences between soil horizons-differences that may be indicative of lithologic discontinuities and soil horizonation. 


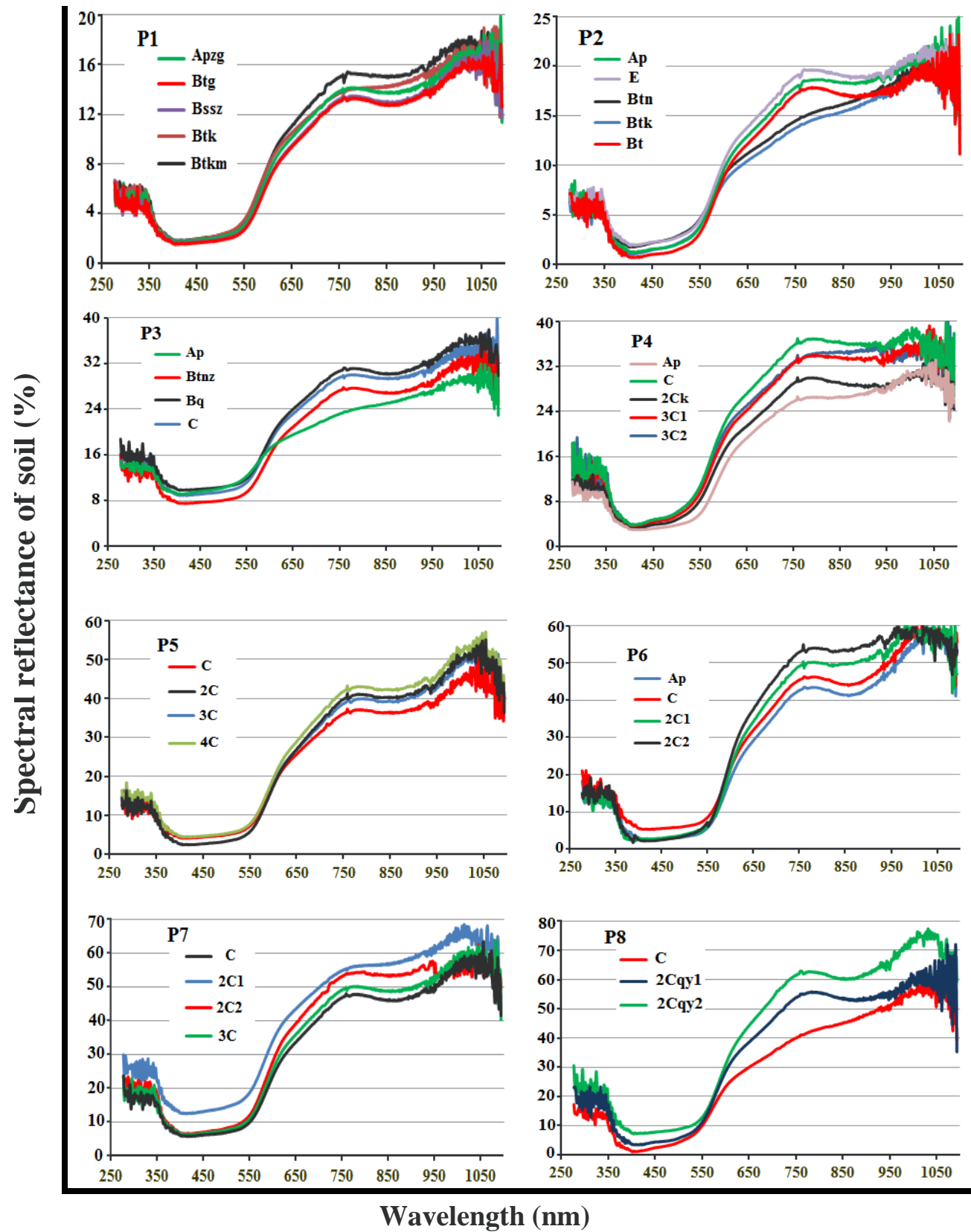

Fig. 4. Raw soil reflectance spectra across wavelengths spectrum used in horizonation prediction for all studied pedons. 
The authors do not endorse the strict use of FPHR elemental data for soil horizon establishment, irrespective of morphological features. However, this sensor provides pedologists with another data stream, quickly and easily acquired in situ, that can help identify areas of lithologic discontinuity and horizonation within a given pedon, whether visually observable or not. Collectively, these proximal sensors can detect depth changes in both organic and inorganic soil constituents, many of which may align with changes in the parent material. Hence, the method may offer insight into the presence of discontinuities that may not normally have been detected in the field. Rather, FPHR sensor is suggested as a tool for detecting or enhancing field morphological horizonation.

\section{Prediction of soil variables}

To further validate the efficiency of the FPHR sensor, twelve soil variables including fractions of clay, silt, and sand, $\mathrm{SOC}, \mathrm{pH}, \mathrm{EC}$, soil available water, gypsum, $\mathrm{CaCO}_{3}, \mathrm{Fe}_{2} \mathrm{O}_{3}, \mathrm{Al}_{2} \mathrm{O}_{3}$, and $\mathrm{SiO}_{2}$ were correlated with soil reflectance at different bands. Summary statistics of Pearson correlation coefficients between soil variables and correlation coefficients between soil variables and reflectance spectra at each band are provided in Tables 2 and 3, respectively. Significant correlations existed among soil variables. Clay was strongly correlated with A.W. ( $\mathrm{r}=0.83)$, SOC $(\mathrm{r}=0.87)$, $\mathrm{Fe}_{2} \mathrm{O}_{3}(\mathrm{r}=0.72), \mathrm{Al}_{2} \mathrm{O}_{3}(\mathrm{r}=-0.51)$ (Table 2). Sand content was negatively correlated with clay $(\mathrm{r}=-0.79)$, SOC $(\mathrm{r}=-0.55)$, and EC $(\mathrm{r}=-0.39)$, and positively with $\mathrm{SiO}_{2}(\mathrm{r}=0.88), \mathrm{Al}_{2} \mathrm{O}_{3}(\mathrm{r}=47)$, silt $(\mathrm{r}=0.42)$, gypsum $(\mathrm{r}=0.33)$, and $\mathrm{CaCO}_{3}(\mathrm{r}=0.29)$ (Table 2). The results in Table 3 revealed that the soil constituents correlated well with the reflectance at different bands based on the absorption and reflection characteristics of each soil constituent by using the correlation coefficient (r). Correlation coefficients between soil variables and reflectance spectra showed both positive and negative correlations at various wavelengths across the calculated bands from the spectrum (Table 3). Clay content correlated negatively with reflectance within the visible range while other soil fractions (silt and sand) correlated positively. The highest negatively significant correlations were found at green bands for clay content $(\mathrm{r}=-0.93)$ and SOC $(\mathrm{r}=-0.83)$, and at NIR band for A.W. $(\mathrm{r}=-0.91), \mathrm{Fe}_{2} \mathrm{O}_{3}(\mathrm{r}=-0.89)$, and $\mathrm{Al}_{2} \mathrm{O}_{3}(\mathrm{r}=-0.89)$. By contrast, the highest positively significant correlations were observed for sand $(r=0.87$ at green band), silt $(r=0.67$ at blue band), gypsum $(r=0.78$ at red band $), \mathrm{CaCO}_{3}(\mathrm{r}=67$ at red band $)$, and $\mathrm{SiO}_{2}(\mathrm{r}=0.64$ at green band). 
Table 2. Pearson correlation coefficients between analyzed soil attributes

\begin{tabular}{|c|c|c|c|c|c|c|c|c|c|c|c|c|}
\hline $\begin{array}{l}\text { Soil } \\
\text { attribute }\end{array}$ & $\begin{array}{l}\text { Sand } \\
\text { (90) }\end{array}$ & $\begin{array}{l}\text { Silt } \\
\text { (96) }\end{array}$ & $\begin{array}{l}\text { Clay } \\
(96)\end{array}$ & $\begin{array}{l}\text { soc } \\
\text { (96) }\end{array}$ & $\begin{array}{c}\mathrm{pH} \\
(96)\end{array}$ & $\begin{array}{l}\mathrm{EC} \\
{ }_{(90)}\end{array}$ & $\frac{\text { A.W. }}{(96)}$ & $c_{\text {gpoum }}$ & $\underset{(90)}{\mathrm{CaCO}_{3}}$ & $\begin{array}{c}\mathrm{Fe}_{3}, \mathrm{O}, \\
(96)\end{array}$ & $\begin{array}{c}\mathrm{Al}_{3} \mathrm{O}, \\
(96)\end{array}$ & $\begin{array}{l}\mathrm{SiO}_{2} \\
(96)\end{array}$ \\
\hline Sand (96) & 1.00 & & & & & & & & & & & \\
\hline Silt (96) & $0.42^{*}$ & 1.00 & & & & & & & & & & \\
\hline $\operatorname{Clay}(96)$ & $-0.79 *$ & $-0.24^{*}$ & 1.00 & & & & & & & & & \\
\hline $\operatorname{soc}(56)$ & $.0 .55^{\circ}$ & 0.05 & $0.87 \%$ & 1.00 & & & & & & & & \\
\hline $\mathrm{pH}(96)$ & -0.11 & -0.04 & 0.11 & $-0.10^{\circ}$ & 100 & & & & & & & \\
\hline EC (96) & $-0.39^{*}$ & 0.07 & $0.41^{*}$ & $0.31 *$ & $.0 .2{ }^{*}$ & 1.00 & & & & & & \\
\hline$A . W(56)$ & 0.08 & $-0.41^{*}$ & $0.833^{*}$ & $0.49^{*}$ & $0.15^{*}$ & $-0.24^{*}$ & 1.00 & & & & & \\
\hline $\begin{array}{l}\text { Gypsum } \\
(96)\end{array}$ & $0.33^{*}$ & -0.02 & -0.12 & $-0.36^{\circ}$ & 0.07 & $0.34^{*}$ & -0.08 & 100 & & & & \\
\hline $\mathrm{CaCO}_{3}(90)$ & $0.29^{*}$ & $0.45^{*}$ & .0 .22 & $-0.54^{*}$ & -0.12 & $0.54^{*}$ & -0.10 & $0.85^{\circ}$ & 100 & & & \\
\hline $\mathrm{Fe}_{2} \mathrm{O}_{2}(96)$ & 0.09 & $-0.62^{*}$ & $0.72^{*}$ & $0.65^{*}$ & 0.13 & -0.08 & $0.62^{*}$ & -0.11 & $-0.47^{\prime}$ & 1.00 & & \\
\hline $\mathrm{Al}_{4} \mathrm{O},(96)$ & $0.47^{\prime}$ & $0.24^{*}$ & $.0 .51^{*}$ & $-0.44^{*}$ & -0.09 & $0.24^{*}$ & $-0.31^{* \prime}$ & 0.12 & $0.71^{*}$ & $.0 .5 T^{*}$ & 100 & \\
\hline sigen (96) & $0.85^{\circ}$ & $0.42^{*}$ & $.0 .39 "$ & $-0.73^{*}$ & -0.05 & $0.1 \%$ & $-0.41^{*}$ & $0.34^{*}$ & $0.57 \%$ & $-0.74^{*}$ & $0.39^{\circ}$ & 100 \\
\hline
\end{tabular}

8*Significant at the level of 0.01 .

* Significant at the level of $l 05$.

Table 3. Correlation coefficients between soil variables and reflectance spectra at each band wavelengths

\begin{tabular}{|c|c|c|c|c|c|c|c|c|c|c|c|c|}
\hline $\begin{array}{l}\text { Soil } \\
\text { attributes }\end{array}$ & $\begin{array}{l}\text { Sand } \\
(9 \%)\end{array}$ & $\begin{array}{l}\text { Silt } \\
(96)\end{array}$ & $\begin{array}{l}\text { Clay } \\
(9 \%)\end{array}$ & $\begin{array}{l}\text { SOC } \\
(9 \%)\end{array}$ & $\begin{array}{l}\mathrm{pH} \\
(9 \%)\end{array}$ & $\begin{array}{l}\text { EC } \\
(9 \%)\end{array}$ & $\begin{array}{l}\text { A.W. } \\
(96)\end{array}$ & $\begin{array}{l}\text { Gypsu } \\
\text { m }(\% \%)\end{array}$ & $\begin{array}{c}\mathrm{CaC} \\
\mathrm{O}_{3} \\
(96)\end{array}$ & $\begin{array}{c}\mathrm{Fe}_{2} \mathrm{O}_{2} \\
(90)\end{array}$ & $\begin{array}{c}\mathrm{Al}_{2} \mathrm{O}_{3} \\
(96)\end{array}$ & $\begin{array}{l}\mathrm{SiO}_{2} \\
(\% 6)\end{array}$ \\
\hline Bloe band & 0.7944 & 0.674 & -0.7544 & $-0.71 * 4$ & $-0.32^{*}$ & 0.25 & -0.6744 & $0.45^{*}$ & 0.14 & -0.15 & -0.24 & $0.45 *$ \\
\hline Green band & 0.8744 & 0.394 & -0.9344 & $-0.834 *$ & -0.24 & $0.34^{*}$ & $-0.594 *$ & $0.31^{*}$ & 0.29 & -0.19 & $-0.41^{*}$ & $0.64 * 4$ \\
\hline Red band & $0.64 * 4$ & $0.42^{*}$ & $-0.69 * 4$ & $-0.47^{*}$ & $-0.45^{*}$ & 0.18 & $-0.81 * 4$ & $0.75 * 4$ & $0.67 * 4$ & $-0.72 * 4$ & $-0.68 * 4$ & 0.28 \\
\hline NIR band & $0.49^{\circ}$ & $0.31^{\circ}$ & $-0.59 *$ & $-0.61^{*}$ & $-0.51 *$ & 0.21 & $-0.91^{*}$ & $0.69 *$ & $0.49^{\circ}$ & -0.95 & $-0.59 \cdot$ & $0.41^{\circ}$ \\
\hline
\end{tabular}

While the lowest significant correlation was obtained for $\mathrm{pH}(\mathrm{r}=-0.51$ at NIR band and EC ( $\mathrm{r}=0.34$ at the green band). Bilgili et al. (2010) evaluated the visible-near infrared reflectance spectroscopy (VNIR) for prediction of diverse soil properties related to four different soil series of the Entisol soil group within a single field in northern Turkey. Bowers and Hanks (1965) similarly reported a decrease in reflectance with increasing particle size.

Reflectance measurements in the laboratory have been used to develop predictive equations for the twelve soil variables at various wavelengths as presented in Fig.5. The spectral features of clays were most prevalent in the blue and green regions (Table 3) where distinctive absorption bands can be used to provide quantitative information on clay minerals. In general, the results concluded that finer soil texture presented as being darker than coarse-textured soils, and consequently soil with sand or silt $(>0.002 \mathrm{~mm})$ had higher spectral 

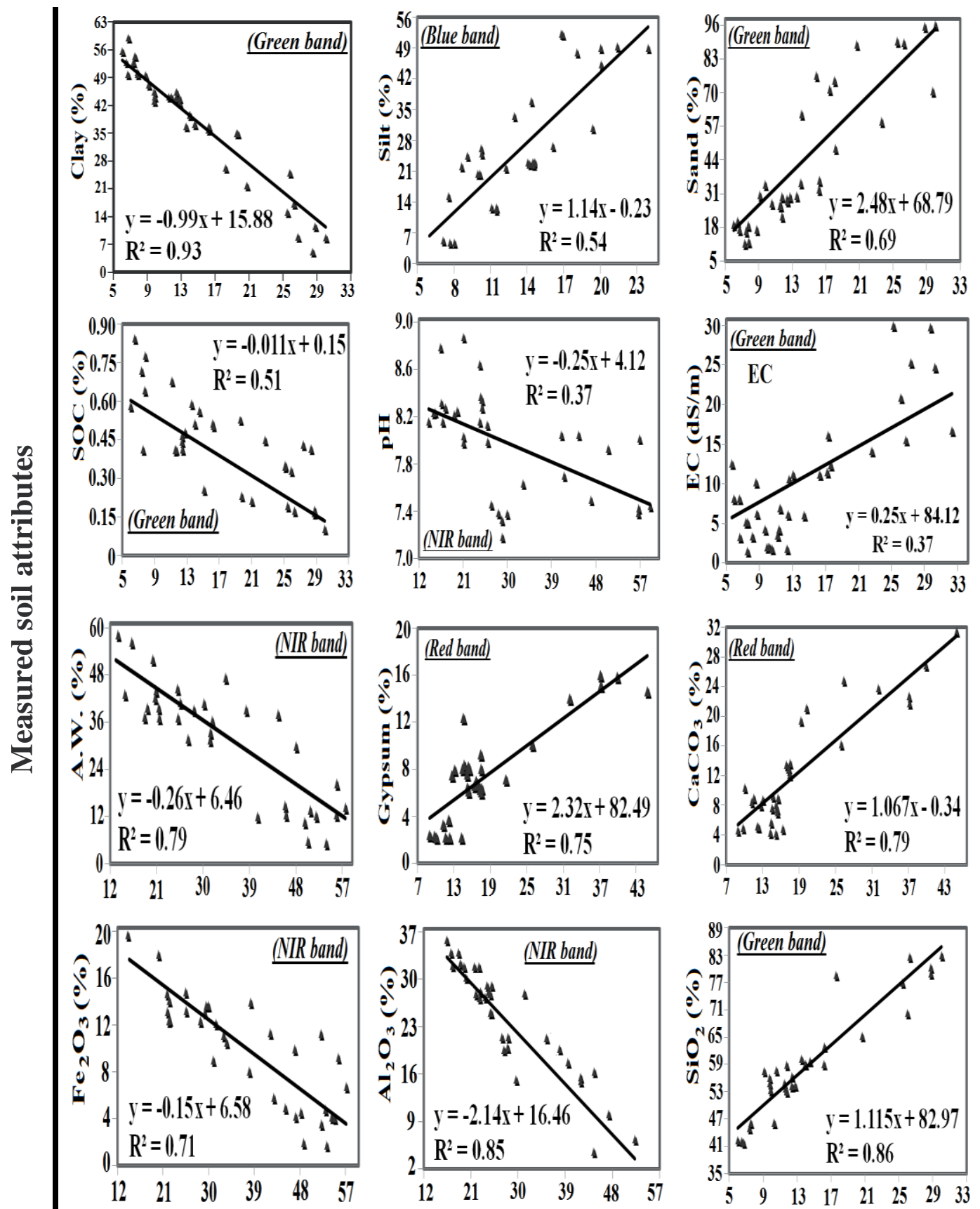

\section{Soil reflectance $(\%)$}

Fig. 5. Regression between measured values and reflectance predictions at VNIR for all soil variables. 
reflectance than clay minerals $(<0.002 \mathrm{~mm})$. Regression between soil measured attributes and VNIR predictions for all soil variables was presented in Fig. 5 showing the most significantly correlated band for each soil property by using regression analyses. The best predictive models were obtained for clay content $\left(\mathrm{R}^{2}=\right.$ 0.93), $\mathrm{SiO}_{2}\left(\mathrm{R}^{2}=0.86\right), \mathrm{Al}_{2} \mathrm{O}_{3}\left(\mathrm{R}^{2}=0.85\right), \mathrm{A} . \mathrm{W} .\left(\mathrm{R}^{2}=0.79\right), \mathrm{CaCO}_{3}\left(\mathrm{R}^{2}=0.79\right)$, gypsum $\left(\mathrm{R}^{2}=0.75\right), \mathrm{Fe}_{2} \mathrm{O}_{3}\left(\mathrm{R}^{2}=0.71\right)$, sand $\left(\mathrm{R}^{2}=0.69\right)$, silt $\left(\mathrm{R}^{2}=0.54\right)$, and $\mathrm{SOC}\left(\mathrm{R}^{2}\right.$ $=0.51$ ). The results showed that most of the spectral responses in the reflective spectrum were significantly related to iron oxide content and soil organic carbon (SOC) that was accurately predicted in the NIR region using reflectance spectroscopy due to their absorption features and the ability to absorb water and nutrients which decreased the reflectance characteristics by this sensor. The silica constituent had a similar trend of sand content (Fig. 5), where the reflectance characteristics of soil were increased due to the presence of a silica component (Bq horizon in P3) (Fig. 2). Inadequate models $\left(\mathrm{R}^{2}<0.50\right)$ were obtained for $\mathrm{pH}$ and $\mathrm{EC}$ (Fig. 5). The poor predictions of $\mathrm{pH}$ and $\mathrm{EC}$ could be attributable to a narrow chemical range, the high skewness of these variables in data sets (Table 1), or poor correlations with primary soil variables such as $\mathrm{CaCO}_{3}$, clay content and organic matter that are more directly assessed by VNIR region. Similar poor predictability for $\mathrm{EC}$ and $\mathrm{pH}$ was found by Chang et al. (2001), Viscarra Rossel et al. (2006), and Bilgili et al. (2010). Although this property may be inherently poorly predicted by VNIR spectroscopy, Shepherd and Walsh (2002) achieved good predictions for $\mathrm{pH}$ with $\mathrm{R}^{2}=0.83$ using soils from eastern and southern Africa.

The results showed that FPHR sensor at VNIR region could classify various soil parameters successfully, assisting with soil management and understanding soil parameter status. Some soil parameters cannot be predicted precisely by the VNIR method, but they can still be classified with reasonable agreement. This can be especially helpful for soil variables that do not have direct relationships with reflectance.

\section{In conclusion}

Traditionally, field soil horizonation has relied on qualitative and semiquantitative data to somewhat subjectively establish horizons with unique features within a given pedon. This process is affected by a range of factors, including the surveyor's experience and knowledge, surveyed locations, weather, field conditions, water table depth, and so on. Use of the FPHR sensor, which quickly determines elemental concentrations on-site, can provide pedologists and field soil scientists with quantitative data useful in differentiating soil horizons. In this study, eight pedons were fully described in 
the field and the horizons were distinguished via traditional morphological description with horizons differentiated by visual examination and hand texturing. Use of FPHR sensor is a promising tool for quantitatively differentiating soil horizons as an enhancement to traditional soil morphological horizonation, or in soils with little observable morphological variability. The method is applicable to a wide range of settings including field use directly on an exposed pedon and analysis of samples in the laboratory.

Furthermore, this study focused on the use of FPHR sensor for predicting such as clay, sand, silt, $\mathrm{SiO}_{2}, \mathrm{Fe}_{2} \mathrm{O}_{3}, \mathrm{Al}_{2} \mathrm{O}_{3}$, gypsum, $\mathrm{CaCO}_{3}$, A.W, pH, EC, and SOC were well predicted using hyperspectral VNIR spectroscopy. The results were generally in line with those of the other studies, even though they were conducted at different scales and in other geographic regions. The comparison of actual lab results and the FPHR estimations showed that in the hyperspectral VNIR region provided the better prediction results for almost all variables. Considering the high spatial variability, and the expensive and timeconsuming measurements of soil properties, VNIR spectroscopy proved to be a useful method to substitute or complement traditional soil analyses and reduce the number of samples to be analyzed for precision management applications in fields. FPHR is rapid, timely, less expensive, non-destructive, straightforward and sometimes more accurate than conventional analysis.

It can also be used as auxiliary information in combination with spatial statistic methods to improve the estimation quality of the parameters and characterization of soil constituents. Further investigations are required to comprehensively evaluate the FPHR under a wider range of soils.

\section{REFERENCES}

Artieda, O., Herrero, J., Drohan, P., 2006. Refinement of the differential water loss method for gypsum determination in soils. Soil Sci. Soc. Am. J., 70 (6): 1932-1935.

Bilgili, A.V., van Es, H.M., Akbas, F., Durak, A., Hively, W.D., 2010. Visible-near infrared reflectance spectroscopy for assessment of soil properties in a semi-arid area of Turkey. Journal of Arid Environments 74: 229-238.

Bowers, S.A., Hanks, R.J., 1965. Reflection of radiant energy from soils. Soil Science, 100: 130-137.

Brown, D.J., Shepherd, K.D., Walsh, M.G., Mays, M.D., Reinsch, T.G., 2006. Global soil characterization with VNIR diffuse reflectance spectroscopy. Geoderma, 132: 273-290. 
Chang, C.W., Laird, D.A., Mausbach, M.J., Hurburgh Jr., C.R., 2001. Near-infrared reflectance spectroscopy-principal components regression analysis of soil properties. Soil Sci. Soc. Am. J., 65: 480- 490.

Elwan, A.A., Sivasamy, R., 2013. Quantification of Desert Soil Constituents using Hyperspectral Radiometer Technique. Zagazig J. Agric. Res., 40 (1): 41-47

Gee, G.W., and J.W. Bauder. 1986. Particle-Size Analysis. p. 383-411. In A. Klute (ed.) Methods of soil analysis. Part 1. Physical and mineralogical methods. 2nd ed. SSSA, Madison, WI.

Jackson, M. L. (1973). Soil chemical analysis. advanced course Ed.2. A manual of methods useful for instruction and research in soil chemistry, Physical Chemistry Of Soil, Soil Fertility And Soil Genesis. Revised from Original Edition (1955). U.S.A.

Janzen, H.H., 1993. Soluble Salts. In: Carter, M.R. (Ed.), Soil Sampling and Methods of Analysis. CRC Press Inc., Florida, pp. 161-166.

Kacar, B., 1994. Soil and Plant Analysis III: Soil Analysis. Ankara University Agricultural Faculty, Ankara, Turkey.

Ludwig, B., Khanna, P.K., Bauhus, P., Hopmans, P., 2002. Near-infrared spectroscopy of forest soils to determine chemical and biological properties related to soil sustainability. Forest Ecology and Management, 171: $121-132$.

McLean, E.O., 1982. Soil pH and lime requirement. In: Page, A.L., Miller, R.H., Keeney, D.R. (Eds.), Methods of Soil Analysis. Part 2. Agronomy Monograph, Vol. 9. American Society of Agronomy, Madison, WI, pp. 199-223.

Minu, S. Shetty, A, Gopal, B., 2016. Review of preprocessing techniques used in soil property prediction from hyperspectral data. Cogent Geoscience, 2: 1145878.

Nelson, D.W., Sommers, L.E., 1996. Total carbon, organic carbon, and organic matter. p. 961-1010. In D.L. Sparks (ed.) Methods of soil analysis. Part 3. Chemical Methods. SSSA, Madison, WI.

Reeves, J., McCarty, G., Mimmo, T., 2002. The potential of diffuse reflectance spectroscopy for the determination of carbon inventories in soils. Environmental Pollution, 116: 277-284.

Reeves, J.B., Van Kessel, J.S., 1999. Investigations into the near-infrared analysis as an alternative to traditional procedures in manure $\mathrm{N}$ and $\mathrm{C}$ mineralization studies. Journal of Near Infrared Spectroscopy , 7: 195212. 
Schaetzl, R.J., and S. Anderson. 2005. Soils: Genesis And Geomorphology. Cambridge Univ. Press, New York.

Schoeneberger, P.J., Wysocki, D.A., Benham, E.C., Soil Survey Staff, 2012. Field book for describing and sampling soils, Version 3.0. Natural Resources Conservation Service, National Soil Survey Center, Lincoln, NE.

Shepherd, K.D., Walsh, M.G., 2002. Development of reflectance spectral libraries for characterization of soil properties. Soil Science Soil Sci. Soc. Am. J., 66: 988-998.

Shibusawa, S., Imade Anom, S.W., Sato, S., Sasao, A., Hirako, S., 2001. Soil mapping using the real-time soil spectrophotometer. In: Grenier, G., Blackmore, S. (Eds.), ECPA 2001, Third European Conference on Precision Agriculture, Vol. 1. Agro Montpellier, pp. 497- 508.

Soil Science Society of America, 2017. Glossary of soil science terms. SSSA, Madison, WI. https://www.soils.org/publications/soils-glossary (accessed 25 November, 2017).

Soil Survey Staff, 2014. Kellogg Soil Survey Laboratory Methods Manual. Soil Survey Investigations Report No. 42, version 5.0. R. Burt and Soil Survey Staff (eds.). Washington DC: U.S. Department of AgricultureNatural Resources Conservation Service.

Udelhoven, T., Emmerling, C., Jarmer, T., 2003. Quantitative analysis of soil chemical properties with diffuse reflectance spectrometry and partial-least square regression: a feasibility study. Plant Soil , 251: 319-329.

Viscarra Rossel, R.A., Walvoort, D.J.J., McBratney, A.B., Janik, L.J., Skjemstad, J.O., 2006. Visible, near infrared, mid infrared or combined diffuse reflectance spectroscopy for simultaneous assessment of various soil properties. Geoderma , 131: 59-75. 


\section{محاولة لتطبيق تقنية الأستشعار الطيفي الفائق في التعرف على بعض صفات التربة}

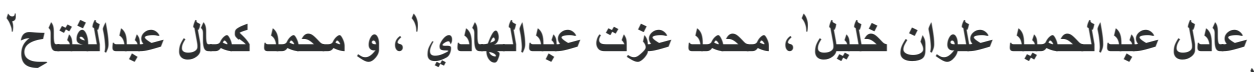
' قسم البيدولوجي، شعبة مصادر المياه والأر اضي الصحر اوية، مركز بحوث الصحر اءء، القاهرة، مصر.

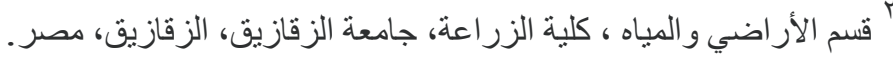

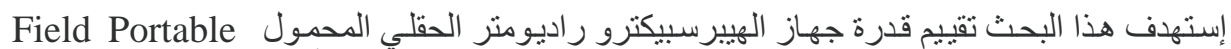
Hyperspectral Radiometer (FPHR)

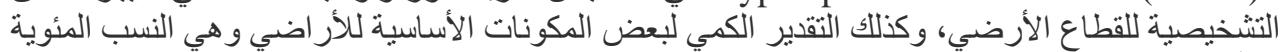

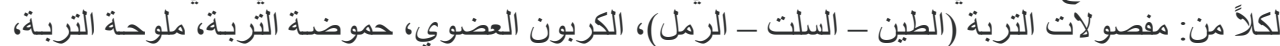

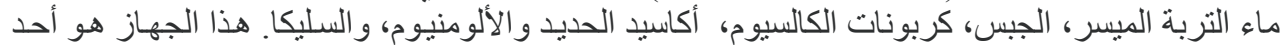

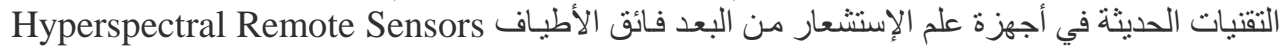

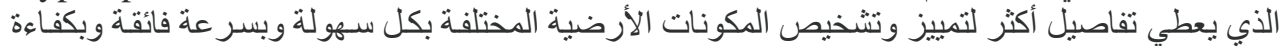

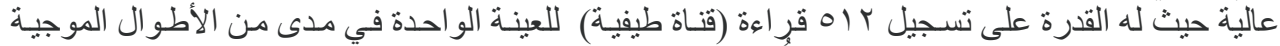

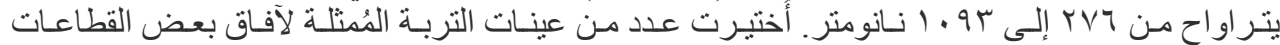

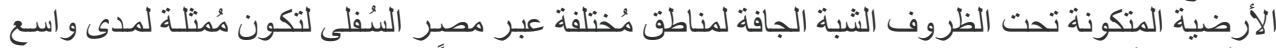

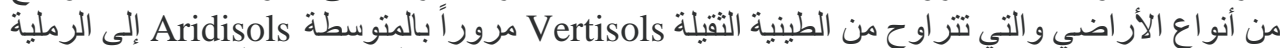

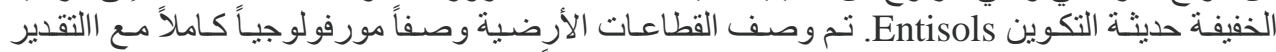

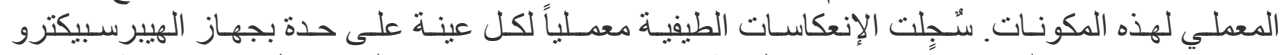

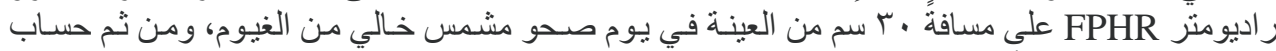

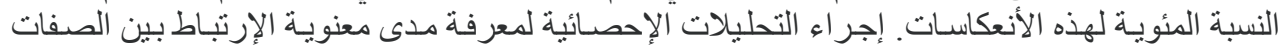

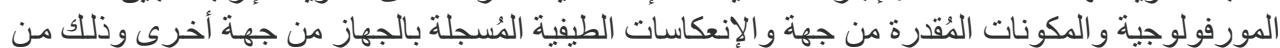
خلال حساب معاملات الإرتباط و الإنحدار.

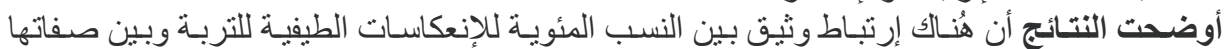

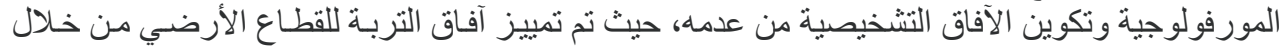

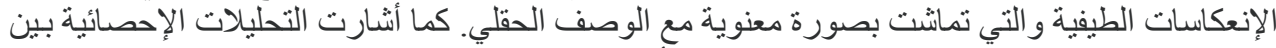

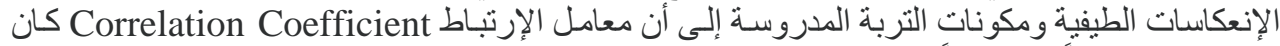

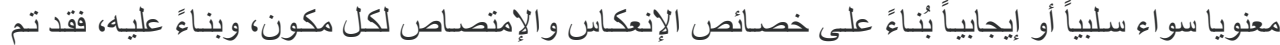

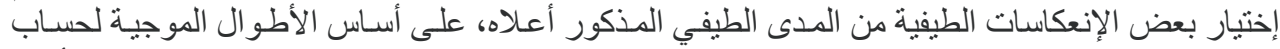

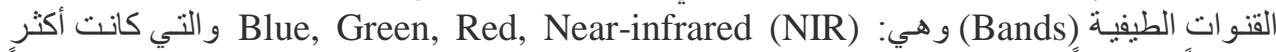

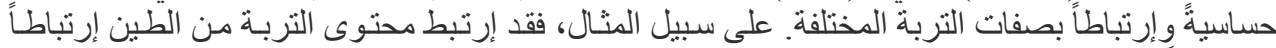

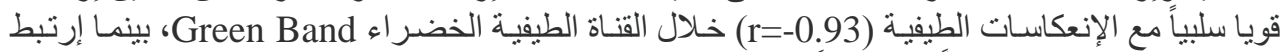

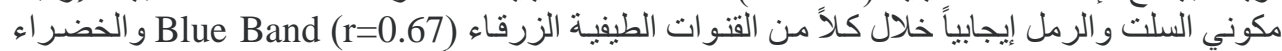

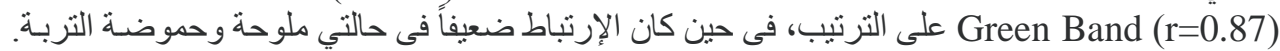

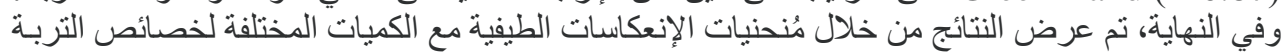

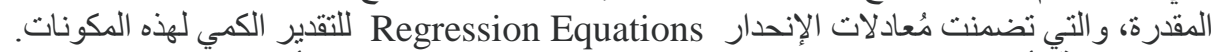

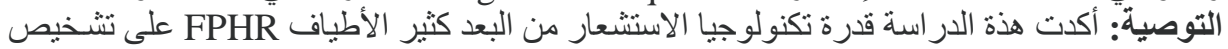

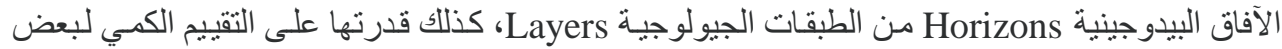

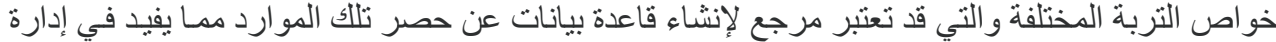

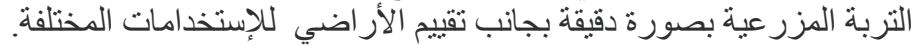

